\title{
Effects of anticoagulants with Danshen on patency of Dacron microprostheses in animal experiments
}

\author{
Ye-Yang Li MD ${ }^{1}$, Tian-Zeng Li MD ${ }^{2}$, Sheng-Quan Zhang MD ${ }^{1}$, Pei-Hong Liang $\mathrm{RN}^{1}$, Xi-Lin Liu MD ${ }^{1}$ \\ ${ }^{\prime}$ Department of Burns and Plastic Surgery, Red Cross Hospital, Jinan University Medical School, \\ ${ }^{2}$ Department of Burns and Plastic Surgery, The First Affiliated Hospital, Sun Yat-Sen University of \\ Medical Sciences, Guangzhou, China
}

\section{Y-Y Li, T-Z Li, S-Q Zhang, P-H Liang, X-L Liu. Effects of anticoagulants with Danshen on patency of Dacron microprostheses in animal experiments. Can J Plast Surg 2001;9(1):11-14.}

To study the effectiveness of anticoagulants, especially those with Danshen, on patency of vascular microprostheses, 20 Dacron microprostheses of $1.2 \mathrm{~mm}$ inner diameter and $15 \mathrm{~mm}$ in length were implanted into femoral arteries of rabbits by using microsurgical techniques for end-to-end anastomosis. Forty rabbits were randomly assigned to either the experimental group or the control group. The experimental group was given anticoagulative therapy. Percutaneous Doppler ultrasound, colour flow duplex, femoral arteriogram, gross inspection and light microscopic examination were used to evaluate the patency of the microprostheses. In the control group, six of the 20 grafts occluded at an early phase and two occluded at a later phase. In contrast, all 20 grafts in the experimental group remained patent four weeks after implantation. Histological examination showed that the grafts in the experimental group were completely re-endothelialized. The present anticoagulative regimen played an important role in preventing the formation of a mural thrombus, which benefited the formation of a neointima in the short term.

Key Words: Dacron; Danshen; Endothelialization; Vascular microprosthesis

\section{Effets des anticoagulants avec Danshen sur la perméabilité des microprothèses de Dacron dans des expériences chez l'animal}

RÉSUMÉ : Pour étudier l'efficacité des anticoagulants, notamment ceux avec Danshen, sur la perméabilité des microprothèses, on a posé 20 microprothèses de Dacron de 1,2 $\mathrm{mm}$ de diamètre intérieur et de $15 \mathrm{~mm}$ de long dans les artères fémorales de lapins à l'aide des techniques microchirurgicales d'anastomoses termino-terminales. Quarante lapins ont été dirigés au hasard vers le groupe de traitement anticoagulant ou vers le groupe témoin. On a eu recours à l'échographie Doppler percutanée, à l'échotomographie Doppler couleur, à l'artériogramme fémoral, à l'inspection macroscopique et à l'examen microscopique classique pour évaluer la perméabilité des microprothèses. Dans le groupe témoin, il y a eu occlusion de six des vingt greffes au début, puis de deux autres greffes plus tard. Au contraire, les vingt greffes étaient toujours perméables quatre semaines après l'intervention dans le groupe expérimental. L'examen histologique a révélé que les greffons, dans le groupe expérimental, avaient été complètement recouverts d'endothélium. Il ressort que le traitement anticoagulant a joué un rôle important dans la prévention de la formation d'un thrombus mural, ce qui a favorisé la formation d'une nouvelle intima à court terme.

A lthough the development of microsurgery has improved resurfacing complicated wounds with various flaps, it also leads to some problems.

The elevation of some flaps, such as forearm skin flaps and posterior tibial artery flaps, satisfies one of two main arteries that supply blood to the extremities. However, some patients feel cold on the distal part of their extremities after operation. The best way to resolve this problem is to reconstruct the excised arteries.

In some surgical procedures, flaps lack enough pedicle length to reach the wound, and harvesting autogenous saphe- nous veins is required to extend the length of the pedicle. However, this procedure is time consuming and involves another donor incision.

To solve the problems mentioned above, vascular prostheses can be used as a substitute for vessel segments. Although large diameter vascular prostheses have been used clinically for more than 30 years with satisfactory patency rates (1), difficulty arises when a small diameter graft is required because of the potential for it to be occluded. Whether a graft remains patent depends on the formation of neointima and the epithelialization on the luminal surface of the graft,

Correspondence: Dr Ye-Yang Li, Department of Burns and Plastic Surgery, Red Cross Hospital, 396 Tongfu Road, central, Guangzhou 510220, China.

Telephone +86-20-8439-2186, fax+86-20-8442-9803, e-mail yeyanglee@hotmail.com 


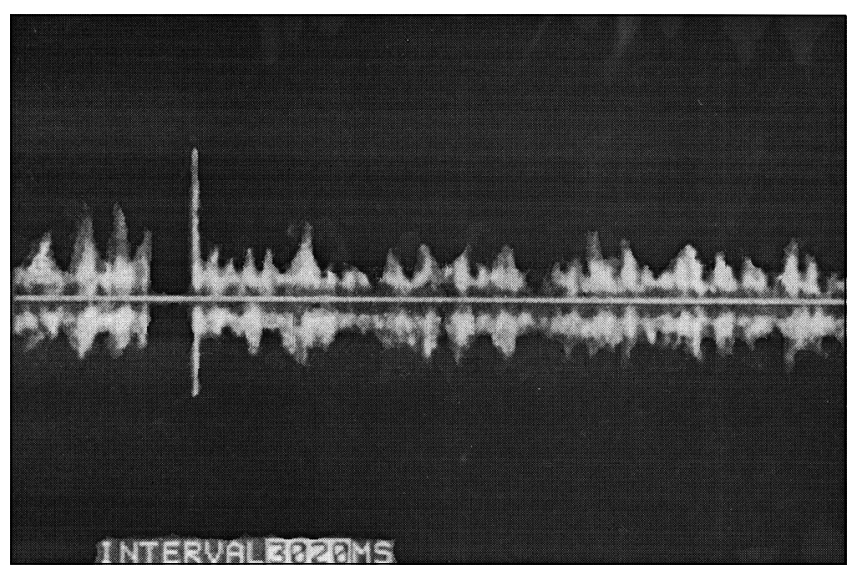

Figure 1) Colour flow duplex examination showed that the variation of the spectrogram of arterial blood flow within the vascular microprosthesis in the experimental group was similar to that of venous bloodflow

whereas endothelial cells seeding in the inner surface may be suitable only for large-calibre synthetic grafts (2). Failure of synthetic vascular grafts with a small inner diameter (less than $2 \mathrm{~mm}$ ), due to pseudointimal hyperplasia thrombosis, is still a common complication $(3,4)$. In addition, the slow blood flow in small-diameter synthetic grafts may facilitate the formation of a mural thrombus, and it remains another major cause of the early failures.

It is well known that anticoagulation therapy can inhibit the formation of attached mural thrombi. Heparin is the most common drug in microsurgery, and Danshen is also a popular drug for preventing vessel thrombosis in China. In the present study, the intent was to determine the effect of Danshen combined with heparin on the patency of small diameter Dacron grafts.

\section{MATERIALS AND METHODS}

\section{Operating technique}

Forty adult New Zealand White rabbits, weighing 3.0 to $3.5 \mathrm{~kg}$, underwent segmental replacement of their femoral arteries with $15 \mathrm{~mm}$ long and $1.2 \mathrm{~mm}$ diameter knitted Dacron grafts (Suzhou Silk Knit Test Factory, China). They were anesthetized by using intravenous pentobarbital (10 to $12 \mathrm{mg} / \mathrm{kg}$ ). Just before operation, the incision site of the thigh was anesthetized locally with $1 \mathrm{~mL}$ of $2 \%$ lidocaine. All the rabbits had an intravenous cannula placed in the marginal ear vein, and lactated Ringer solution was infused during surgery, averaging $100 \mathrm{~mL}$ for each procedure.

Under the operating microscope, the femoral artery was exposed and dissected free from surrounding structures. Branch vessels were controlled with bipolar diathermy. The artery was ligated proximally and distally, and a $12 \mathrm{~mm}$ segment of the artery was removed. A Dacron prosthesis, $15 \mathrm{~mm}$ long with a $1.2 \mathrm{~mm}$ internal diameter, was placed as an interposition graft, end-to-end, with eight interrupted 10-0 monofilament nylon sutures. Before implantation, the grafts were immersed in heparinized saline solution. Leaks were controlled with additional sutures. On completion of the anasto- mosis, the distal clamp was removed and the backflow of blood was ascertained before removal of the proximal clamp. Immediate patency of the graft was assessed by palpation and visual pulsatile flow in the distal femoral artery. The patency trial was performed on the artery distal to the anastomosis to document flow in an antegrade direction. The mean clamping time of the femoral artery was $20 \mathrm{~min}$. Implantation was done by using an operating microscope and sterile instruments. Each rabbit was housed individually under controlled environmental conditions with free access to water and food (pellets).

The rabbits were randomly assigned to either the control group or the experimental group, resulting in 20 rabbits in each group. Both groups were given $300 \mathrm{U}$ heparin anticoagulation therapy intravenously twice daily, from one day before surgery to seven days after implantation, and the experimental group was also given $1 \mathrm{~mL}$ of Danshen solution (extracted from the root of red-rooted salvia) each time. Graft patency was evaluated by using palpation and a Doppler flowmeter (Polysonics, USA) daily for one week and then twice weekly.

Four weeks after implantation, three rabbits in each group underwent operation again along the original incision under systemic anesthesia, and a cannula was inserted proximally into the femoral artery to perform an arteriogram. The other three rabbits in each group were measured by ultrasound using a colour flow duplex. All rabbits were operated on to investigate the patency by gross inspection. The entire specimen, including the graft and recipient vessels, was then removed and fixed in $10 \%$ formalin solution at room temperature. The specimen was then embedded in paraffin, sectioned longitudinally to include the length of the graft with both anastomoses and sectioned transversely to inspect the integrity of their intima morphologically. Sections were stained with hematoxylin eosin.

\section{RESULTS}

All animals survived the experiment. There was no evidence of ischemic deterioration in the operating limbs. On the first day after implantation, percutaneous Doppler ultrasound was used to determine the patency of the Dacron graft until four weeks after surgery. In the control group, four Dacron segments two days after surgery and two Dacron segments three days after surgery had no beat sound by Doppler flowmeter. Colour flow duplex examination showed that these grafts were obstructed. Gross inspection confirmed that these grafts were occluded due to thrombosis in proximal anastomoses, which accounted for $30 \%$ of the failures in the control group. No other occluded grafts were found afterwards in both groups. Moreover, venous variation in spectrogram was observed in patent grafts (Figure 1). Four grafts that had confirmed patency by Doppler flowmeter from the control group and experimental group, respectively, were chosen to have a femoral arteriogram. The grafts from the control group showed a slight stricture, and the remaining grafts from the experimental group showed smoothness along the luminal wall (Figure 2). 


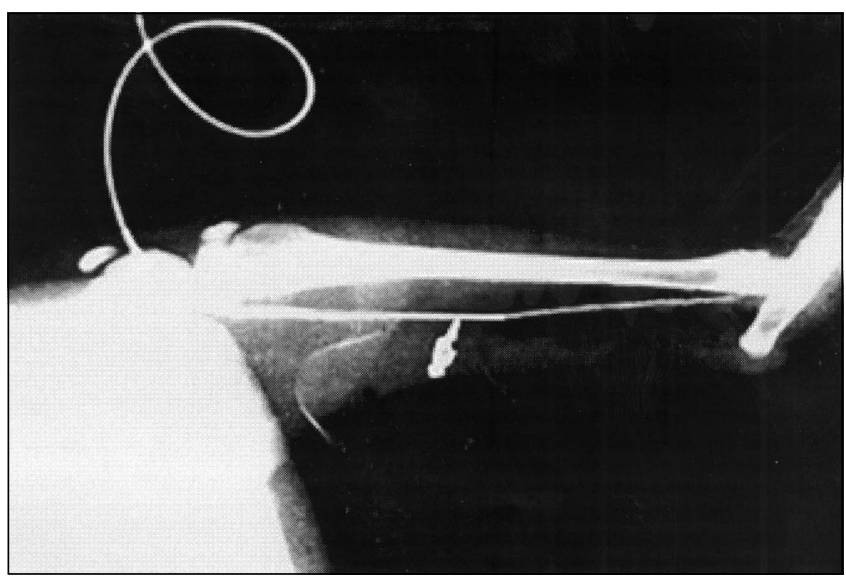

Figure 2) X-ray of the femoral arteriogram showed patency of the graft. The luminal surface was smooth

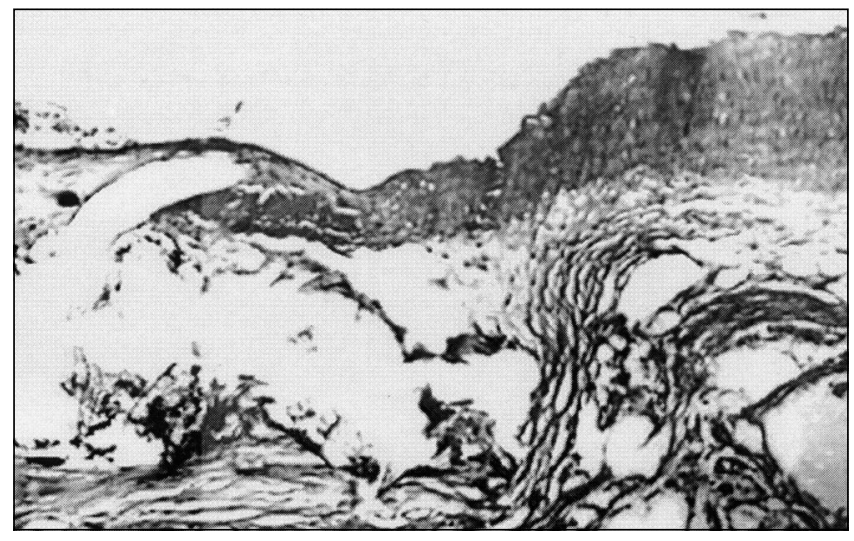

Figure 3) The proximal and distal ends of the vascular microprosthesis were connected to the adjacent artery (hemotoxylin and eosin stain, original magnification $\times 80$ )

\section{Histological studies}

Experimental group: Light microscopic examination of transverse and longitudinal sections of grafts removed at week 4 showed close connection between the grafts and vessels in the proximal and distal anastomoses (Figure 3). The inner surfaces of the grafts were covered with a layer of thin, elaborate, neoformative connective tissue, which was lined by a layer of intact endothelial cells connecting to the same cells of adjacent vessels. Their size and shape were similar to the endothelial cells of the artery intima (Figure 4). There was a layer of thicker and denser neoformative fibrous tissue surrounding the graft. These neoformative fibrous tissues were also seen growing into the small interstices between Dacron fibres in the graft wall, which connected the fibrous tissues of intima and extima (Figure 4). There was no foreign body giant cell and no evidence of an inflammatory reaction. Control group: The remaining grafts, except for the six occluded grafts, were examined with light microscopy. The luminal surface of the neointima was scarcely covered with endothelium. Some thrombi were adherent to the nonendothelialized inner surface that was composed of lamellae of platelets and fibrin, with erythrocytes and leukocytes inter-

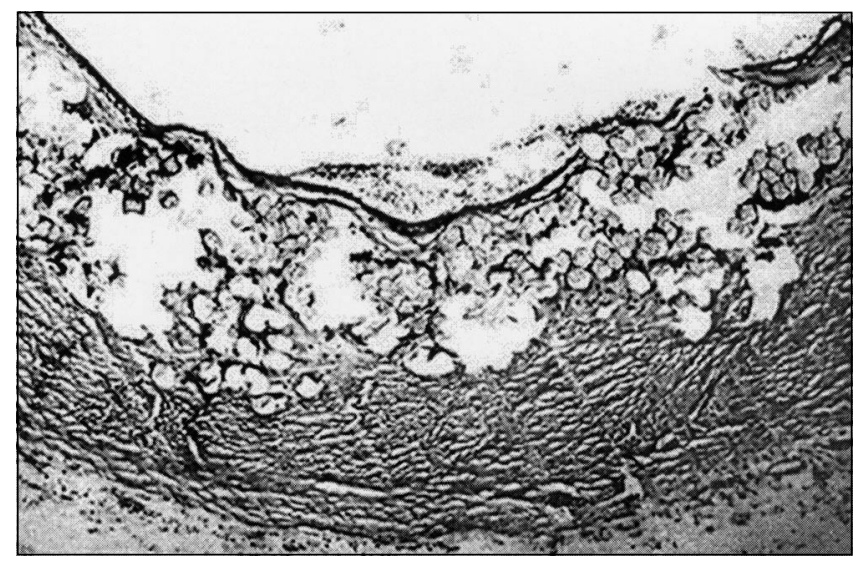

Figure 4) The inner surface of the vascular microprosthesis was covered with thin and fine neoformative fibrous tissue, and a layer of endothelium covered over this structure with a shape and size that was the same as those of the endothelium of the adjacent artery (hemotoxylin and eosin stain, original magnification $\times 80$ )

spersed. These nonendothelialized areas were mainly in the central portion of the graft.

\section{DISCUSSION}

Large-diameter vascular prostheses have been used clinically for many years with satisfactory patency rates, but the patency of small internal diameter grafts is still low and uncertain. Occlusion is the main problem affecting the use of small vascular prostheses, and it mainly results from pseudointimal hyperplasia, thrombosis and infection. Some authors consider that the risk of thrombosis and infection will be reduced by rapid endothelialization and good incorporation of implanted grafts because a layer of endothelial cells on the inner surface will decrease graft thrombogenicity and bacterial adherence (5-7). Actually, it was not very difficult to avoid infection by using a strict aseptic technique in the experiment. There was no evidence of graft infection in any specimen of our experiment. The material, inner surface structure, pore size of the wall of the prostheses and blood flow rate inside it are also known to influence re-endothelialization $(3,8)$. What influence does anticoagulation therapy exert on the patency rate of vascular prostheses under the same condition, other than the factors mentioned above? Previous attempts to improve patency of small diameter grafts, including acetylsalicylic acid (9), dipyridamol (10), ibuprofen (11), prostacyclin (12) and heparin (13) have not shown consistent or clinically reliable results. Owing to this reason, we made an attempt to increase the patency rate of small-diameter prostheses with the regimen of Danshen and heparin, and excellent results were achieved. The mechanism of heparin has been well known for many years, but Danshen is not well known in countries other than China. Danshen is the Chinese name for Salvia miltiorrhiza Bunge, mainly composed of tanshinone I and tanshinone II. Experimental studies confirmed that it can dilate the coronary artery, increase blood flow inside the coronary artery, reduce the heart rate, decrease blood viscosity and increase the velocity of blood 
flow inside the vessel (14). In China, it is widly used after microsurgery.

The patency of vascular prostheses depends on epithelization of the luminal surface. Any exposed site of luminal surface is liable to result in thrombosis and occlusion in the graft. These complications frequently occur in the first three days after grafting, according to our observation of the control group.

The source of the tissue for the inner capsule is of critical importance in determining the potential future clinical efficacy of the prosthesis. There are three main hypotheses for synthetic graft endothelialization.

\section{- Migration of endothelial cells from arterial or venous} edges over the graft. Berger et al (15) observed the variation of neointima at multiple time points in the prosthesis and noted consistent epithelialization from the anastomoses.

- Capillary ingrowth through graft interstices. Howard et al (16) suggested that the formation of inner capsule tissue is a result of transinterstitial migration. They observed the immature mesenchymal cells in the interstices of the prosthesis and of an inner capsule in specimens. These cells developed into various characteristic mature cells (8).

- Deposition of circulating endothelial cells. Mackenzie et al (17) considered that round cells in the blood may be undifferentiated multipotential cells that may differentiate into various mature cells. We believe that epithelium migration from the arterial edge is the main source for re-endothelialization of the inner surface because the sections' examinations confirmed that a layer of intact endothelial cells covering the inner surface of the graft linked up with the epithelium of the adjacent arteries in our experiment. In occluded grafts of the control group, some epithelial cells were also observed growing only onto the end of graft from vessel edges.

The occlusion of prostheses frequently occurred in the first week after operation, according to our observations. The graft segment was likely to be re-endothelialized, provided that thrombosis did not occur in the vascular prosthesis in the first week. Low blood circulation and formation of attached mural thrombi in the small diameter vascular prostheses are the most important causes of graft failure. Sharp (18) considered that any vascular prosthesis that maintained patency over three weeks could be regarded as having long term patency.

\section{CONCLUSIONS}

There was a significant difference in the patency rate at week 4 between the experimental group and the control group in the present study. Satisfactory patency rates in the experimental group showed the effectiveness of the regimen of an- ticoagulation therapy used. Therefore, the authors have reason to believe that Danshen can prevent thrombosis in a graft, owing to its ability to both decrease the viscosity of blood and increase the speed of blood flow. The anticoagulant regimen used has a potential future in microprosthesis grafting.

ACKNOWLEDGEMENTS: This work was supported by a grant for medical reseach from the Guangzhou Municipal Health Bureau.

\section{REFERENCES}

1. Nordestgaard AG, Buckels JAC, Wilson SE. A laboratory model for the evaluation of thromboembolic complications of small diameter vascular prosthesis. Br J Exp Pathol 1986;67:839-49.

2. Zdanowski Z, Ribbe E, Bengmark S. Endothelialization of microporous polytetrafluoroethlylene grafts in the infrarenal aorta and caval vein of the rat. Microsurgery 1992;13:277-86.

3. Hess F, Jerusalem C, Braun B, Grande P. The inner prosthetic surface structure and re-endothelialization: An experimental study in the rat using two types of microvascular prostheses for aortic implantation. Microsurgery 1986:7:29-37.

4. Sbarbati R, Gianessi D, Cenni MC, Lazzerini G, Verni F, De Caterina F. Pyrolitic carbon coating enhances Teflon and Dacron fabric of patibility with endothelial cell growth. Int J Antif Organ 1991;14:491-8.

5. Moore WS, Malone JM, Keown K. Prosthetic arterial graft material: Influence on neointimal healing and bacteremic infectibility. Arch Surg 1980;115:1379-83.

6. Birinyi LK, Douville EC, Lewi SA, Bjornson HS, Kempczinski RF. Increased resistance to bacteremic graft infection after endothelial cell seeding. J Vasc Surg 1987;5:193-7.

7. Ortenwall P, Wadenvik H, Kutti J, Risberg B. Endothelial cell seeding reduces thrombogenicity of Dacron grafts in humans. J Vasc Surg 1990;11:403-10.

8. Clowes AW, Kirkman TR, Reidy MA. Mechanisms of arterial graft healing. Rapid transmural capillary ingrowth provides a source of intimal endethelium and smooth muscle in porous PTFE prostheses. Am J Pathol 1986;123:220-30.

9. Allen BT, Sparks RE, Welch MJ. Reduction of platelet deposition on vascular graft using an antiplatelet graft coating technique. J Surg Res 1984;36:80-8.

10. Hancock JB, Forshaw PL, Kaye MP. Gore-tex (polytetrafluoroethylene) in canine coronary artery bypass. J Thorac Cardiovasc Surg 1980;80:94-101.

11. Kaye MP, Gloviczki PG, Dewanjee MK, Claus PL, Lovaas ME. Ibuprofen in experimental vascular surgery. Am J Med 1984;77:95-101.

12. Callow AD, Connolly R, O'Donnell TE, et al. Platelet-arterial synthetic graft interaction and its modification. Arch Surg 1982;117:1447-54.

13. Barry KJ, Scott RM, Keough EM. Heparin and small caliber polytetrafluoroethylene grafts in the carotid arteries of rats. J Microsurg 1981;3:72-6.

14. Public Health Ministry's Pharmacopedia Committee of PRC. The Pharmacopedia of People's Republic of China, Beijing: People's Medical Publishing House, 1990:62.

15. Berger K, Sauvage LR, Rao AM, Wood SJ. Healing of arterial prostheses in man: Its incompletenness. Ann Surg 1972;175:118-27.

16. Howard PG, James WD, Eric DE, Joan Ellinger, Karolyn FB, Dae Un Kim. Derivation of neointima in vascular grafts. Circulation 1988;78(Suppl I):I6-12.

17. Mackenzie JR, Hackett M, Topuzlu C, Tibbs DJ. Origin of arterial prosthesis lining from circulating blood cells. Arch Surg 1968;97:879-83.

18. Sharp WV. The carotid artery: A test site for small vessel prosthetics. J Surg Res 1970;10:41-6. 